\title{
The Home Mortgage Disclosure Act And Subprime Lending
}

Rakesh K. Gupta, Federal Reserve Board, USA

Hari Sharma, Virginia State University, USA

Cheryl E. Mitchem, Virginia State University, USA

\begin{abstract}
This research paper focuses on the analysis of subprime lending activities in specific geographic area in the light of reporting requirements of the Home Mortgage Disclosure Act (HMDA). This cross sectional study has focused on the detailed analysis of mortgage data for the selected Metropolitan Statistical Areas (MSA) from a socio-economic perspective. The objective of this research is to assess the impact of predatory lending in selected geographic regions. Another dimension of the research focuses on the role of mortgage lending from a securitization point of view. The study reveals that private securitization (PSEC) mortgages grew dramatically not only by the number of loans but also significantly by the dollar amount due to subprime lending activities during the period of study. The growth in PSEC loans affected mortgage lending in several ways, such as, increasing subprime lending, boosting home prices, and undermining mortgage industry regulations. Additionally, Government-Sponsored Enterprises (GSEs) loan originations also increased the number of subprime loans because of relaxed reporting requirements which contributed to increased delinquencies and foreclosures for conforming loans. The study further reveals that HMDA reporting requirements allowed the mortgage industry to conceal the loans that had spreads above the prime rate of up to 3.5 points for Fixed Rate Mortgage or 5 points for Adjustable Rate Mortgage (ARM). The study of mortgage lending programs, products, and regulatory laws have also been examined to assess the impact of predatory lending on homeownership.
\end{abstract}

Keywords: Subprime, HMDA, MSA, PSEC, GSE, Mortgage Lending

\section{INTRODUCTION}

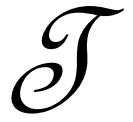

he historical background of home financing reveals that there have been challenges and opportunities that have attracted researchers to understand, analyze, and forecast the future of the mortgage industry.

The Home Mortgage Disclosure Act (HMDA) was enacted in 1975 by Congress to protect consumers and lenders. The Federal Reserve Board (FRB) implemented the HMDA through Regulation C to collect and examine mortgage data from lenders on home loans. The act requires lending institutions to provide public lending data to the Federal Financial Institutions Examination Council (FFIEC). The FFIEC segments the data into different categories for each Metropolitan Statistical Area (MSA). Since 1980, the HMDA has gone through several amendments (McCoy, 2007). Initial amendments focused on requiring the reporting of additional characteristics as well as including more lenders and financial institutions in the reporting requirements.

The U.S. Congress enacted the Home Ownership and Equity Protection Act (HOEPA) in 1994, to amend the Truth in Lending Act (TILA), to minimize abusive lending practices in the home-equity lending market. The HOEPA law addresses certain deceptive and unfair practices in home-equity lending covering primarily refinancing and home-equity installment loans. The law also empowered the FRB to adjust Regulation $\mathrm{C}$ to meet the requirements. In 1994, Regulation C was amended to make HMDA data available to the public earlier to improve the accuracy of the HMDA data as well as clarify and simplify the reporting requirements. 
There have been several amendments to the Regulation $\mathrm{C}$ to increase disclosures through technological innovations and provide higher levels of analysis to protect lenders and consumers. For example, in 1997 the FRB, on behalf of the FFIEC, designed the HMDA Data Entry System Software to assist respondents in automating the filing of the HDMA data. In 2002, a major amendment to the regulation required lenders to report data items related to loan pricing and loan originations in which the annual percentage rate exceeded the yield for comparable treasury securities by a specific threshold amount. These thresholds are the spreads above the prime rate of three percent for the first lien or five percent for subordinate lien loans. In subsequent years, most of the changes to Regulation C were related to asset exemptions thresholds.

The explosion of subprime lending during the period 2004 - 2007, forced the FRB to amend Regulation C to be in compliance with the amendments of Regulation Z (TILA) that defined "higher-priced mortgage loans" to better protect consumers and facilitate responsible lending. The final rule to amend Regulation $\mathrm{Z}$ came into existence in July 2008 to prohibit unfair or abusive lending practices. Subsequently, the FRB published an amendment to Regulation C (HMDA) to revise the rules for reporting price information on higher-priced loans to conform to the definition of "higher-priced mortgage loan". Under the amended rule, the lender is required to report the spread between the loan's annual percentage rate (APR) and a survey-based estimate on APRs currently offered on prime mortgage loans of a comparable type if the spread above the prime rate is greater than or equal to 1.5 percentage points for a first-lien loan or 3.5 percentage points for a subordinate-lien loan. The final rule's effective date was October 1, 2009 and made the compliance mandatory for loan applications taken on or after that date or for loans that close on or after January 1, 2010, regardless of their application dates. The additional characteristics, such as, amortization type (fixed versus adjustable) are required to be reported.

The purpose of this study is to analyze the HMDA data for the period $2004-2006$ for selected MSAs to understand the subprime mortgage activities given the disclosure requirements during the period. Subprime lending is defined as loans that don't meet the federal guidelines for conforming loans as determined by Federal National Mortgage Association (Fannie Mae) and Federal Home Loan Mortgage Corporation (Freddie Mac). The idea of subprime lending was intended to increase homeownership to minority, lower and moderate income (LMI), and ethnic groups who otherwise might not be able to qualify for a traditional mortgage loan because of their past credit problems and income levels. The remaining sections of this study include a literature review, a discussion of the research method and the results of the analysis of mortgage lending on home ownership trends for the study group. The conclusions and recommendations discuss key observations and results from the data analyses. Additionally, concluding remarks and recommendations for future studies are also provided.

\section{LITERATURE REVIEW}

Canner, Passmore and Laderman (1999) examined subprime and prime lending trends in the 1990s. For the period between 1993 and 1998, the authors found that subprime home loans accounted for 17 percent of the overall growth in home lending. However, the growth rate varied significantly among lower income neighborhoods and predominantly minority population neighborhoods with subprime lending growth rates of 26 percent and 36 percent, respectively. Rosenbaum (1996) analyzed mortgage data from an ethnicity and income perspective for the New York-New Jersey-Long Island metropolitan area as well as New York City. These findings suggested that the Black and Hispanic families were less likely to live or own in high-quality housing units and neighborhoods than white families. Hogarth and O'Donnell (2000) assessed the holdings of financial products among LMI households, such as, credit cards, first mortgages, car loans, consumer loans, certificate of deposits, and Individual Retirement Accounts (IRAs). The study revealed that having a transaction account was a key determinant in the holding of credit and saving products. Engel and McCoy (2002) conducted a detailed study of the laws pertaining to predatory lending practices and the economic impact of predatory lending on the affected households. Calem, Gillen and Washter (2003) conducted a study about the neighborhood distribution of subprime mortgage lending focusing on Chicago and Philadelphia. The research findings noted that in both cities nearly $50 \%$ of the growth in subprime lending was due to an increase in African-American homeowner population across neighborhoods. The AfricanAmerican borrowers, regardless of the neighborhood, had a relatively higher likelihood of obtaining a subprime loan. Less-educated (non-degreed) persons were also found to turn to subprime mortgages due to their lack of knowledge or sophistication. Calem, Hershaff and Wachter (2004) expanded their research to include seven cities in designing a model of prime versus subprime loan allocations in 1997 and 2002. Calem et al. (2004) focused on 
studying the effect of neighborhood racial and ethnic composition on the likelihood of receiving a subprime loan. The findings revealed that the individual's race, ethnicity, and income were significant in subprime borrowing.

Harvey and Nigro (2004) investigated whether the North Carolina predatory lending laws of 1999 influenced mortgage lending in North Carolina in comparison with other southeastern United States using HMDA data for the period 1998 - 2000. The findings revealed that the North Carolina law reduced subprime lending activity. Ho and Pennington-Cross (2006) conducted research on the impact of local predatory lending laws on the flow of subprime credit and discussed the enactment of laws, including HOEPA, which intended to reduce predatory and abusive lending and control the flow of loan originations. The empirical results of the study demonstrated that typically local predatory laws tend to reduce loan application rejections, with little impact on the flow (loan application and origination) of credit. However, the strength of the HOEPA law had a strong impact on both, the flow of credit and loan application rejections. Reade (2006) presented a summary for the New England MSA describing the impact of HDMA on loan activities focusing on traditionally underserved populations categorized as LMI households and minorities. The findings suggested that the overall lending activity increase in recent years had been driven primarily by increasing the volume of applications from LMI and minority households and that the gap between whites and minorities (Blacks and Hispanics) widened both in originations and denial rates. The gap was even wider for LMI families as compared to higher income levels. Bostic, Engel, McCoy, Pennington-Cross and Wachter (2007) studied state and local anti-predatory lending laws and the evidentiary effect on predatory lending. The results of their analysis supported the view that anti-predatory lending laws influenced subprime lending markets. However, the subprime market dynamism was so complex that anti-predatory laws were not adequate to address the restrictions, coverage, and enforcement components. Shiller (2007) attempted to analyze recent trends in home prices and home ownership in order to forecast future home prices and determine the impact on the local economy. Shiller (2007) concluded that it is not improbable that we may see large real price decline of residential homes extending over many years in major cities that have seen large increases.

Bostic and Lee (2008) examined the question of whether the promotion of the home ownership strategy for building wealth among LMI families through various policies was a prudent decision. The decision was further analyzed by examining the net benefits of home ownership over renting. The net benefits were categorized into; the importance of down payments, housing price appreciation, and mortgage instrument risk.

Since LMI households are unlikely to manage the resources to provide an adequate down payment, the mortgage instrument risk was found to result in the distress of managing monthly payments, delinquencies, and eventually foreclosures. Mayer and Pence (2008) reviewed data from various sources to characterize subprime lending and studied the dispersion of subprime mortgages in different parts of the United States. The research findings noted that no standard definition can be established for subprime lending. Bocian, Ernst and Li (2008) examined whether race and ethnicity of the borrower played any role in subprime loan pricing after the objective metrics were accounted for by analyzing 2004 HMDA data and a proprietary database of securitized subprime loans. The authors conducted statistical analysis as well as multiple regression analysis to ascertain whether conforming to conventional mortgage guidelines had any impact on mortgage prices. The findings showed that the minority borrowers were more likely to get higher-rate subprime mortgages than non-Latino white borrowers.

In 2010, Okah and Orr studies subprime mortgage lending in New York City between 2004 and mid-2007. They found that the loans were clustered in neighborhoods where African-Americans and Hispanics constituted a relatively large share of the population.

\section{RESEARCH METHOD}

This study utilizes the triangulation research techniques that include both qualitative and quantitative research methods for analyzing data available from various sources. These sources include research studies and data from the Mortgage Banker Association (MBA), FRB, and FFIEC. The qualitative premise of the study synthesizes authentic research material available for the study group in published research conducted by financial institutions and academicians. The research done by financial institutions are available through the FRB, the MBA, and Loan Performance and HMDA websites. The quantitative aspect of the study requires mathematical and statistical analyses to address the research question using aggregate data from HMDA website for a three year period (2004 - 
2006). The data prior to this period does not meet Regulation $\mathrm{C}$ and Regulation $\mathrm{Z}$ reporting requirements. The aggregate data includes information on loans sold by the characteristics of borrowers; pricing information for first lien loans; dispositions of loan applications for the Federal Housing Administration (FHA), the Veterans Administration (VA), and conforming programs. The mathematical and statistical analyses include data segmentation, summarization, averages, percentages, and trends analysis. The results are presented in table, graph, and chart forms. The study further compares the performance of home purchases by categroies (minority, ethnic and LMI families) as defined by HMDA from Washington, DC, Richmond and Virginia Beach, Virginia MSAs to the national trends.

\section{RESULTS}

We examined mortgage loan data for the study group in Richmond (RICH) and compared closely with the corresponding data in two selected MSAs of Virginia--(1) Virginia Beach-Norfolk-Newport News (VA BCH) and (2) Washington-Arlington-Alexandria (WASH). The data has been analyzed and compared to assess the impact of mortgage lending activities on the study groups. Additionally, these trends have been compared with national averages.
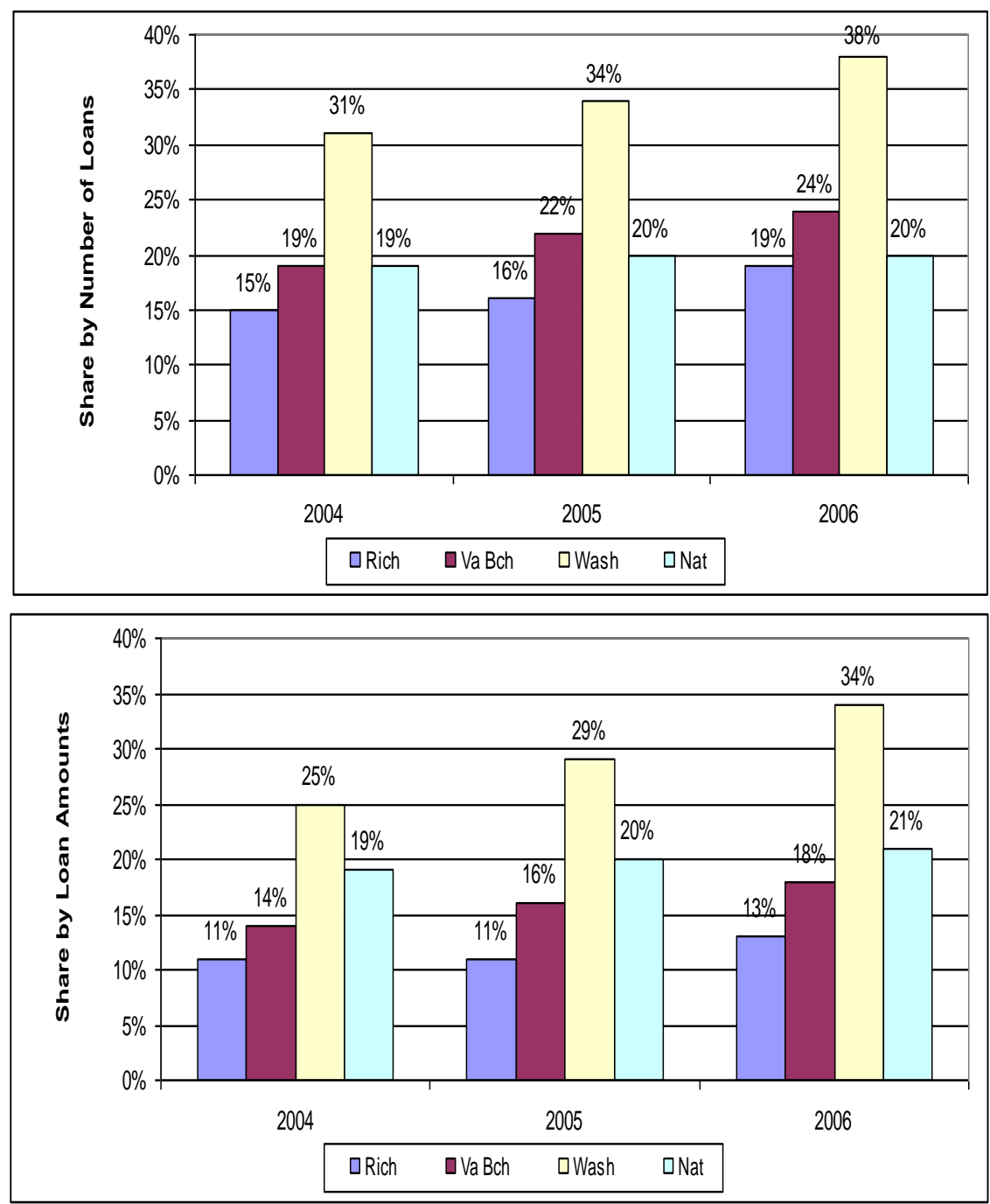

Figure 1: Share of Loan Originations by Minority Group 


\section{Analysis of Loan Originations by Minority Group}

Figure 1 shows that the percentage of mortgage loans by number of loans increased in the selected MSAs for the minority group. The percentage increases from $2004-2006$ in minority share of loan originations by loan count increased in Richmond (4\%), VA Beach (5\%), Washington (7\%) and nationally (1\%) while the increase by dollar volume in Richmond was (2\%), VA Beach (4\%), Washington (9\%) and nationally (2\%). The percentage increases, in volume by count as compared to volume by amount, suggests that number of borrowers from the minority group increased during the period of study. However, Richmond exhibited slower growth than the selected MSAs.

\section{Analysis of Loan Originations by Ethnic Group}

Figure 2 shows that the percentage of mortgage loans by number of loans increased in the selected MSAs of Virginia for the Ethnic group. The percentage increase from 2004 - 2006 in minority share of loan originations by loan count increased in Richmond (1\%), VA Beach (0\%), Washington (4\%) and nationally (2\%) while the increase by dollar volume was Richmond (1\%), VA Beach (0\%), Washington (4\%) and nationally (3\%). The percentage increases, in volume by count as compared to volume by amount, suggests that number of borrowers from minority group increased for Richmond during the period of study while other MSA did not exhibit similar trend.
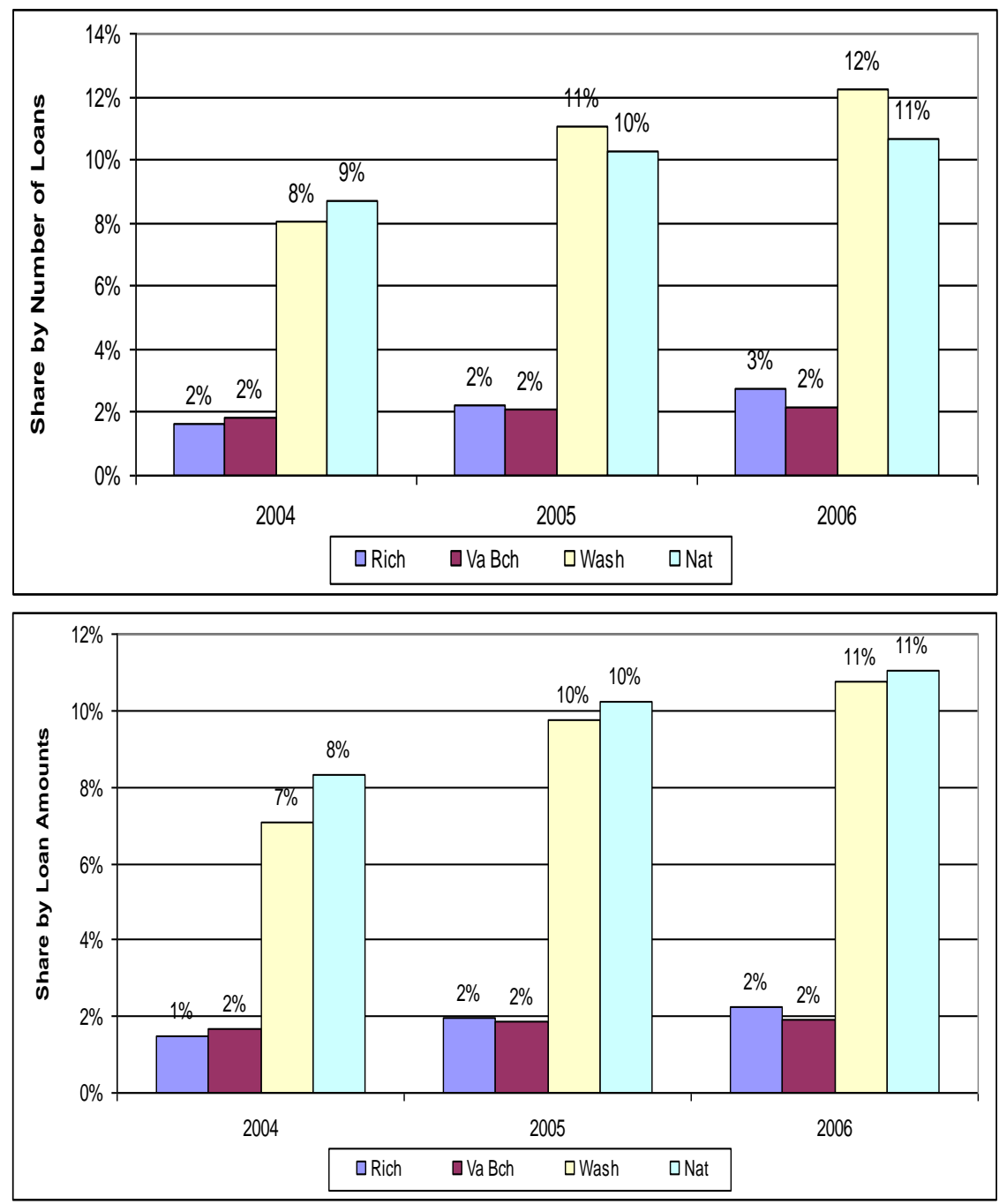

Figure 2: Percent Comparison of Ethnic Group Lending by Loan Originations 


\section{Analysis of Loan Originations by LMI Group}

A comparison of the mortgage activity in various MSAs and with national averages is shown in Figure 3 by determining the percentage share of the LMI group by number of loans and dollar values of loan amounts. The trend shows that the percentage of mortgage loans by number of loans increased in all selected MSAs of Virginia and nationwide averages for the LMI group.
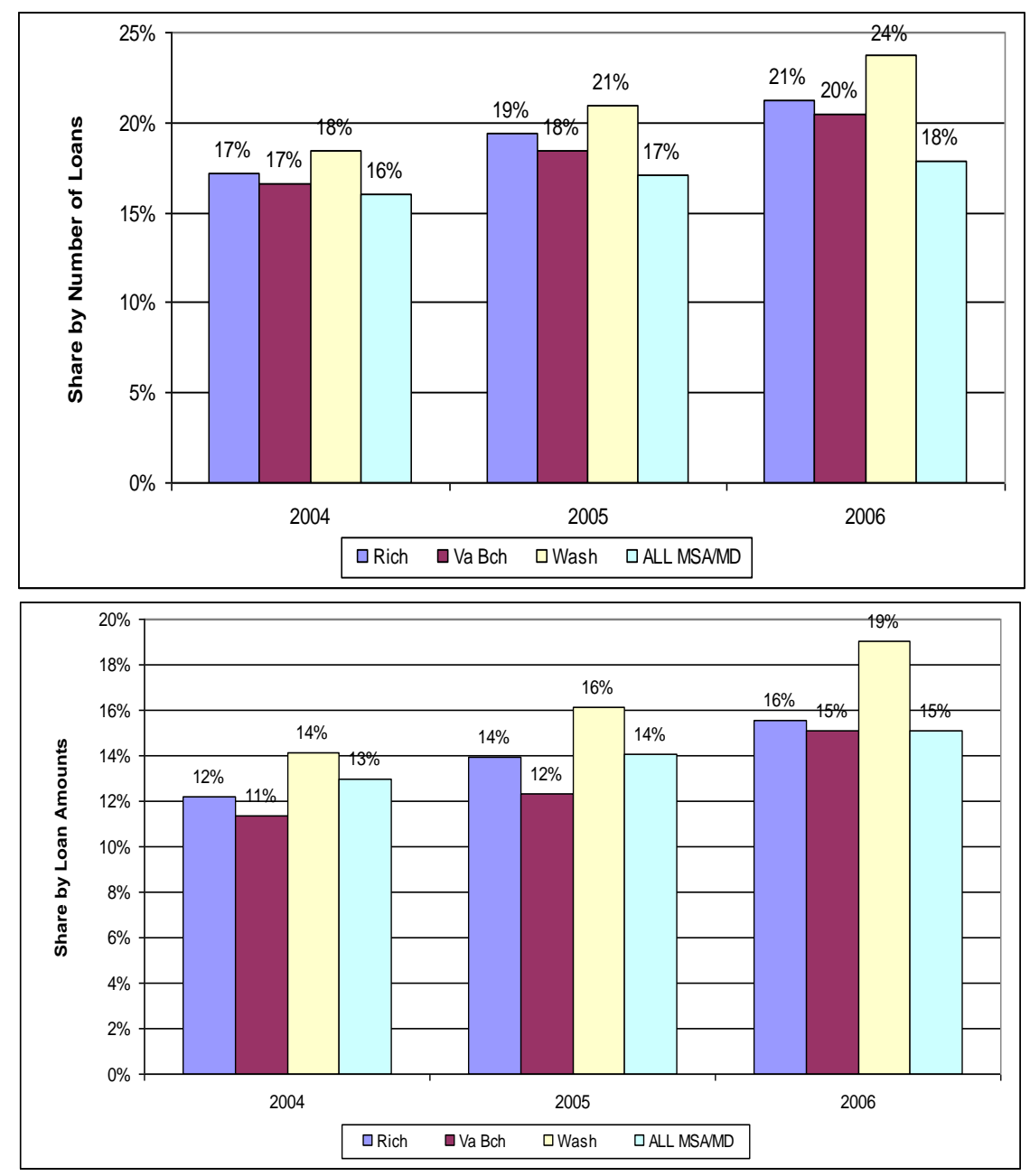

Figure 3: Percent Comparison of LMI Group Lending by Loan Originations

\section{Analysis of Subprime lending activity (Loan Count) by Lender Category}

Figure 4 shows the trend by percent share of lenders in subprime loans by number of loans. The trend shows that the share of subprime loans increased for Private Securities (PSEC) and commercial banks, insurance, and affiliates (CBIA) lender types from 3\% and 38\% in 2004 to $20 \%$ and $41 \%$ at the cost of Government Securities Enterprise (GSE) and other lender types whose share dropped from 3\% and 56\% in 2004 to 3\% and 36\% in 2005. The combined effect on the lenders share in 2005 resulted in a gain of $20 \%$ by PSEC and CBIA lenders at the expense of GSEs and other lenders in Richmond for all subprime lending. The trends continued in 2006 and were comparable to the national trends. 


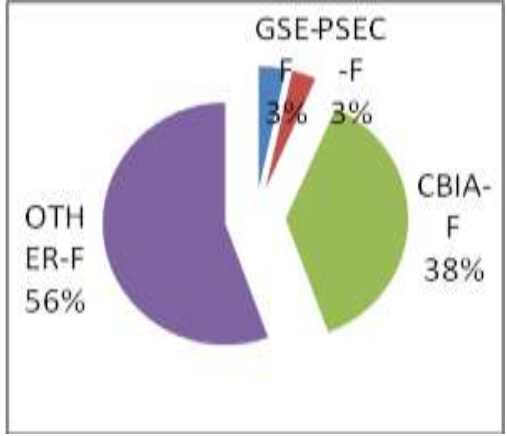

2004

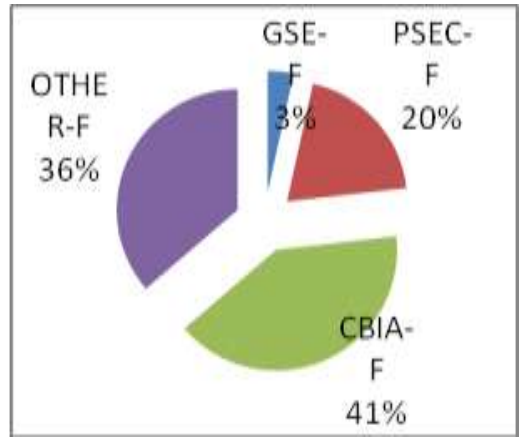

2005

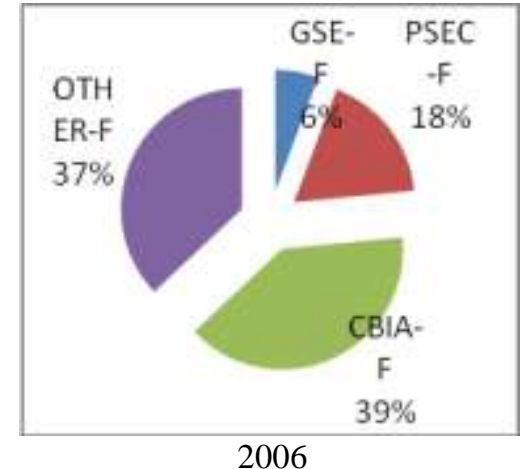

2006

Figure 4: Percentage Comparison of Subprime Lending by Number of Loans Richmond

In figure 5, the trend of percent share of subprime lenders by dollar value of mortgages is reviewed by lender category for Richmond. The trend for the percent share by dollar value of mortgages is similar to that of the percent share by number of loans where the share of PSEC and CBIA increased at the cost of the other lender types primarily. The total gain of 24\% from a combined share of 37\% for PSEC and CBIA lender types in 2004 to $61 \%$ in 2005 was from the other lender category in Richmond. The trend continued into 2006 and remained comparable to the nationwide averages.

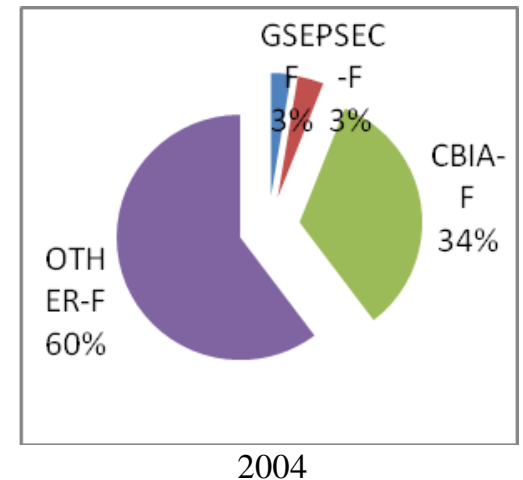

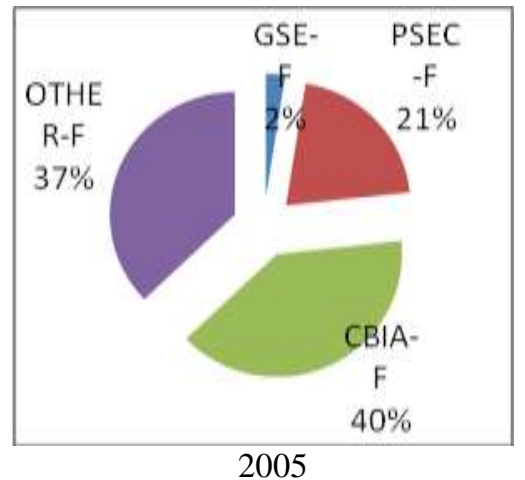

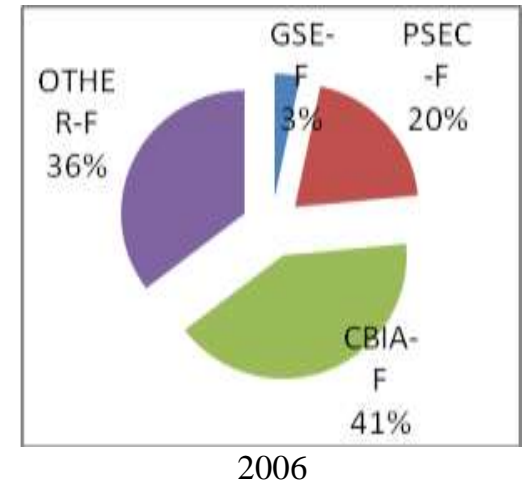

2006

Figure 5: Percent Comparison of Subprime Lending by Loan Amounts Richmond

The aggregate data for HOEPA status loans, i.e., high-cost loans, extracted from the HMDA website (Table 1) shows the number of such mortgages in Richmond, in selected MSAs in Virginia, and in all MSAs nationwide. In terms of number of loans, lenders in the Other Category played a major role financing HOEPA status loans in the study period for each group considered for the study. However, in 2004, Richmond had more GSE financed HOEPA mortgages than the remaining lender types. HOEPA status mortgages surged 3 to 10 times to their highest level, during $2004-2005$ period, in each MSA of the study group. These mortgages dropped to their lowest levels in 2006 for each MSA group of the study.

Table 1: Number of HOEPA Status Loans

\begin{tabular}{|l|c|c|c|c|}
\hline & Richmond MSA & VA Beach MSA & Washington MSA & All MSA \\
\hline 2004 & 11 & 41 & 31 & 4,049 \\
\hline 2005 & 147 & 161 & 250 & 13,772 \\
\hline 2006 & 5 & 12 & 27 & 1,354 \\
\hline
\end{tabular}


In terms of dollar value of HOEPA status loans, Table 2 shows, once again, that the lenders in the other category provided most of the financing during the study period in each MSA of the study.

Table 2: Amount of HOEPA Status Loans in Thousands

\begin{tabular}{|l|c|c|c|c|}
\hline & Richmond MSA & VA Beach MSA & Washington MSA & All MSA \\
\hline 2004 & $\$ 1,002$ & $\$ 5,235$ & $\$ 8,068$ & $\$ 627,969$ \\
\hline 2005 & $\$ 18,543$ & $\$ 22,035$ & $\$ 64,741$ & $\$ 2,060,854$ \\
\hline 2006 & $\$ 510$ & $\$ 1,897$ & $\$ 6,280$ & $\$ 223,012$ \\
\hline
\end{tabular}

The CBIA lender category followed the other category in supplying the funding for HOEPA status loans nationwide. The dollar value of HOEPA status loans surged during $2004-2005$ while dropping to their lowest levels in 2006. The impact of subprime lending for Richmond is studied by lender categories - GSE, PSEC, CBIA, and other for first liens only. The trends by lender category have been close to national trends. Since GSEs provide more risk disclosures and satisfy more demanding capital stress tests than PSEC, CBIA, and other lender categories, therefore, the subprime share of GSEs was the lowest (3\%-6\%) among all lender types. The growth in subprime lending during the study period is attributed to very aggressive efforts of subprime lenders which are grouped in the PSEC category. Subprime lending has been exhibited in CBIA and Other categories as well that represented an evolution of the credit markets towards efficiency and maximum utilization of consumer deposits to reap maximum profits.

The analysis of HOEPA status loans reveals that Richmond experienced similar growth and decline in such loans consistent with the remaining MSAs of the study group and nationwide. The growth of HOEPA status loans prompted a public backlash against the predatory lending practices of mortgage lenders. Regulation $\mathrm{Z}$ strengthened the mortgage lending laws against predatory lending and was instrumental in the decline of HOEPA status loans. Due to tremendous growth in subprime lending activities, there has been some impact on the delinquencies and foreclosures in Richmond. A recent monthly trend from August 2007 to April 2008, has been studied to compare and contrast the findings for Richmond with the selected MSAs of Virginia and national trends. The data for Figure 6 and Figure 7 is extracted from the Loan Performance website.

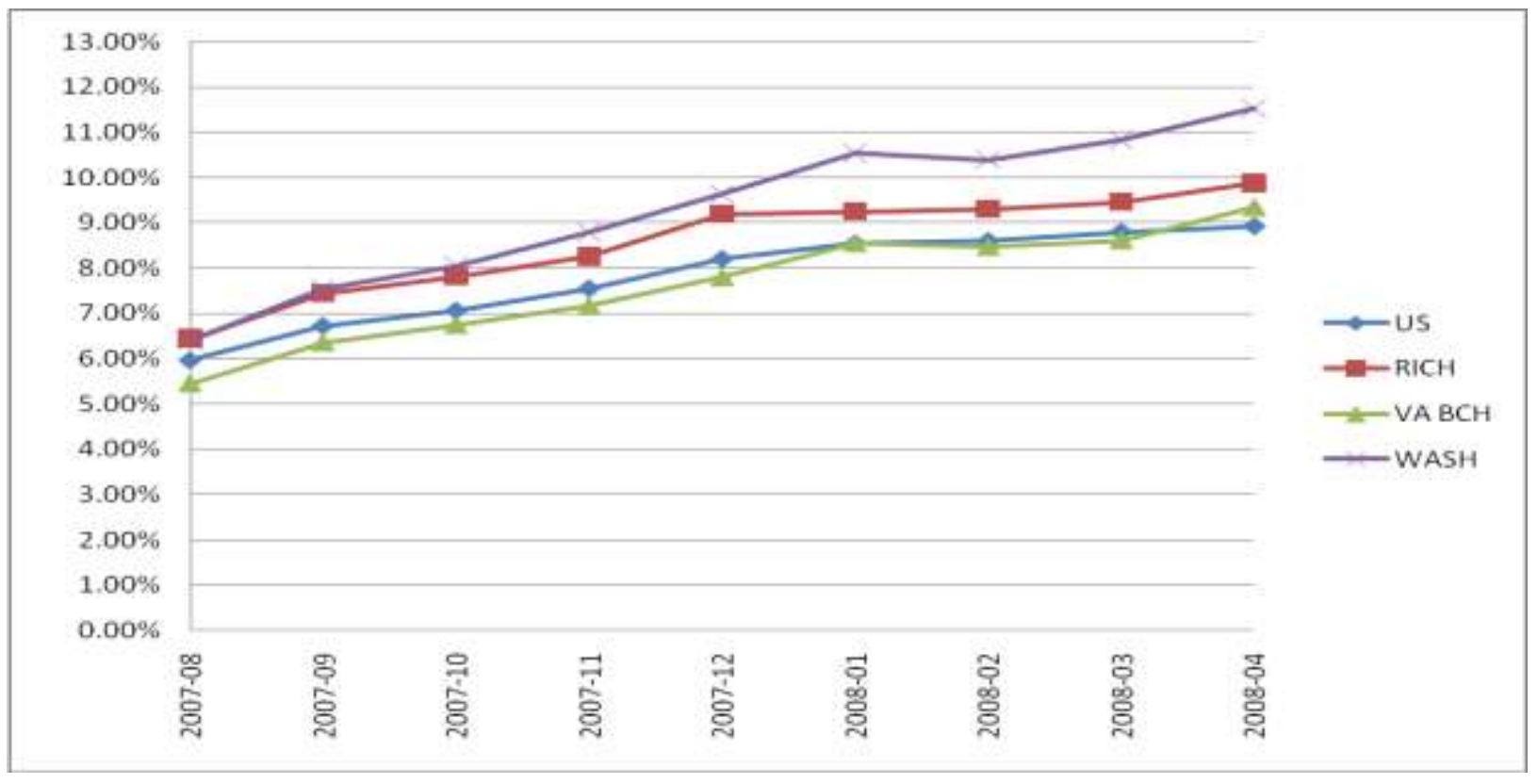

Figure 6: Percent Comparison of Loan Delinquencies 
Figure 6 shows the trends in the delinquencies of subprime mortgages, which include those mortgage loans where the borrower is 90 days or more behind in payments. The trends show that the delinquencies of subprime mortgages in Richmond increased from 6.44\% in August 2007 to 9.87\% in April 2008.

In comparison, the delinquencies for $\mathrm{VA} \mathrm{BCH}$ area and national averages were below Richmond, starting at 5.45\% and 5.98\% in August 2007 and growing to $9.36 \%$ and $8.93 \%$ in April 2008 respectively. However, the trend for WASH area shows that the delinquencies increased from $6.40 \%$ in August 2007 to $11.52 \%$ in April 2008 and were considerably higher than Richmond. With the exception of WASH and VA BCH area, which showed a slight month-to-month decline from January 2008 to February 2008, all MSA/MDs selected for Virginia and the national trends showed a month-to-month increase in the percent share of delinquencies.

Figure 7 shows the foreclosure trends for the 9-month period, from August 2007 to April 2008. The Figure 7 highlights the foreclosure trends nationwide. The nationwide foreclosures increased from $6.23 \%$ in August 2007 to $10.23 \%$ in April 2008. These foreclosure percentages of subprime loans were the highest for this period as compared with all MSAs selected for Virginia. The foreclosures increased from August 2007 to April 2008 period for WASH, from $4.03 \%$ to $7.58 \%$ in March 2008 and dropping down to $7.31 \%$; for VA BCH, from $1.78 \%$ to $3.92 \%$ in March 2008 and dropped down to 3.74\%; and for RICH, from 2.33\% to 3.90\% in February 2008 and dropping down to $3.59 \%$. Richmond had the lowest percent of subprime delinquencies in April 2008 in comparison to the selected MSAs of Virginia and corresponding U.S. national averages.

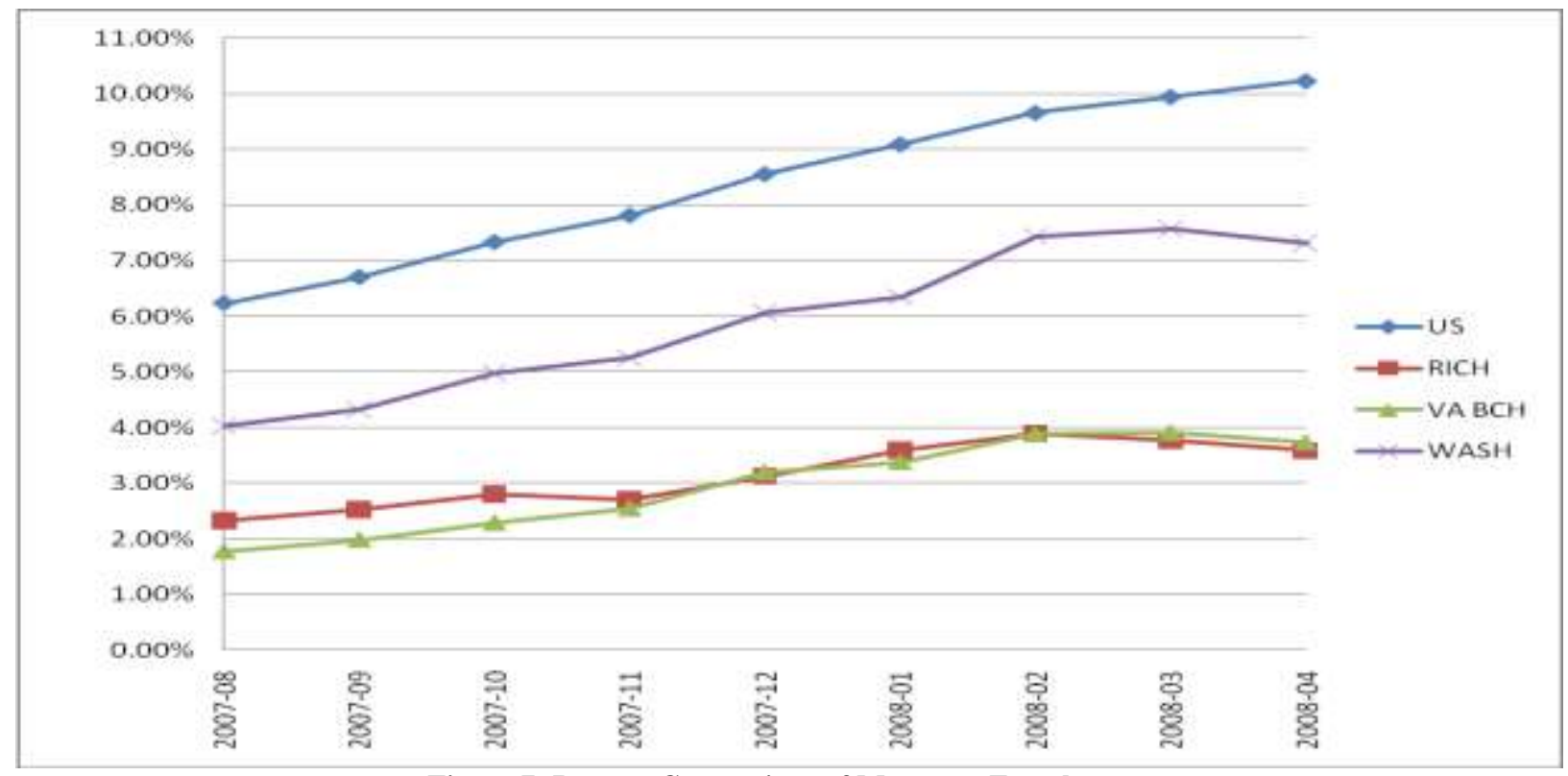

Figure 7: Percent Comparison of Mortgage Foreclosures

The analysis of delinquencies and foreclosures for Richmond brings some insight into the impact of mortgage lending including subprime loans due to the limited reported data by mortgage lenders. Delinquencies for Richmond have been higher than the national averages and VA Beach, but lower than Washington. The result of higher delinquencies is attributable to subprime lending, where most of the loans were originated with the lowest monthly payments and with increased frequency of resetting monthly payments in subsequent years. However, unemployment rate and demographic mix did not change significantly and appears not to have impacted adversely the delinquencies. The analysis of foreclosures for Richmond reveals contrary results for delinquencies where foreclosures had been the lowest in 2008 as opposed to national and Washington foreclosure trends. However, the lowest foreclosure rate in 2008 is not necessarily limited to the loans in Richmond that were originated during the study period, $2004-2006$. 


\section{CONCLUSIONS AND RECOMMENDATIONS}

The study of different mortgage lending programs and products reveals that all programs and products have been equally available to all borrowers in all MSAs. The qualifications of mortgage lending, including the lending limits for FHA, VA, conforming and non-conforming loans, as well as regulatory and statutory requirements were similar to most of the MSAs. Borrowers benefited from the interest rate spread between Fixed Rate Mortgage and Adjusted Rate Mortgage products and the prevailing interest rates in choosing from various mortgage products during the study period. The study from the perspective of minority, ethnic, and LMI groups shows that private securitization (PSEC) grew dramatically not only by the number of loans but also significantly by the dollar amount. The increase in PSEC and GSEs loan originations affected mortgage lending in several ways, such as, increasing Non-prime (subprime) lending, boosting home prices, and undermining mortgage industry regulations. Since GSEs require more risk disclosures and satisfy more demanding capital stress tests than PSEC, CBIA, and other lenders, therefore, the subprime share of GSEs was the lowest among all lender types. The HOEPA requirements exposed high cost loans that prompted a public backlash against predatory lending practices of mortgage lenders. Regulation $\mathrm{Z}$ strengthened the mortgage lending laws against predatory lending and was instrumental in the decline of HOEPA status loans in 2006.

Since lenders were not required to report loans separately that had spreads above the prime rate of up to 3.5 points for Fixed Rate Mortgage or 5 points for Adjustable Rate Mortgage, the majority of subprime loans were blended in all lender categories. The presence of subprime loans in all categories is well supported by the evidence of increased delinquencies and foreclosures in subsequent years. The majority of growth in PSEC lender category for the study groups also suggests that the study group preferred private lenders over GSEs for their mortgage needs due to lower borrowing qualifications as well as lower mortgage lending rates.

The authors intend to focus on further study that requires delinquencies and foreclosure data in subsequent years for the loans originated during the period of this study. The recent revisions in Regulation $\mathrm{Z}$ have narrowed the above prime spread for identifying non-prime loans. This provision offers further research opportunities to assess the impact on non-prime lending.

Mian and Sufi (2008) suggested that greater securitization of subprime mortgages leads to house price appreciation. This assertion provides a basis for further research to validate or contradict their findings in the light of recent amendments of Regulation Z. The trends of recent mortgage lending activities and loan servicing data, will also allow researchers to ascertain why some lending institutions did better in recent housing market than other lenders.

\section{AUTHOR INFORMATION}

Rakesh Gupta is a Senior Database Administrator at the Federal Reserve Board in Washington, D.C.

Hari Sharma is an Associate Professor in the Department of Accounting and Finance in the Reginald F. Lewis School of Business at Virginia State University.

Cheryl Mitchem is the Assistant Dean in the Reginald F. Lewis School of Business at Virginia State University and an Associate Professor in the Department of Accounting and Finance.

\section{REFERENCES}

1. Bocian, D.G., Ernst, K.S. and Li, W., (2008), "Race, ethnicity and subprime home loan pricing", Journal of Economics and Business, Vol. 60, pp. 110-124.

2. Bostic, R. W. and Lee, K. O., (2008), “Assets and Credit Among Low-Income Households”, American Economic Review: Papers \& Proceedings, Vol. 98, No. 2, pp. 310-314.

3. Bostic, R. W., Engel, K. C., McCoy, P. A., Pennington-Cross, A. N., and Wachter, S. M., (2007), "State and Local Anti-Predatory Lending Laws: The Effect of Legal Enforcement Mechanisms", http://ssrn.com/abstract=1005423 
4. Calem, P. S., Gillen, K., and Wachter, S., (2003), "The Neighborhood Distribution of Subprime Mortgage Lending", U of Penn, Inst for Law \& Econ Research Paper 03-39, http://ssrn.com/abstract=478581

5. Calem, P. S., Hershaff, J.E., and Wachter, S., (2004), "The Neighborhood Distribution of Subprime Mortgage Lending", U of Penn, Inst for Law \& Econ Research Paper 04-14, http://ssrn.com/abstract=583102

6. Canner, G.B., Passmore, W. and Laderman, E., (1999), “The Role of specialized Lenders in Extending Mortgages to Lower-Income and Minority Borrowers", Federal Reserve Bulletin, November.

7. Engel, K. C. and McCoy, P. A., (2007), "Turning a Blind Eye: Wall Street Finance of Predatory Lending", Fordham Law Review, Vol. 75, pp. 101-164, http://ssrn.com/abstract=910378

8. Harvey, K. D. and Nigro, P. J., (2004), "Do Predatory Lending Laws Influence Mortgage Lending? An Analysis of the North Carolina Predatory Lending Law", Journal of Real Estate Finance and Economics, Vol. 29, No. 4, pp. 435-456.

9. HMDA Aggregate Reports, http://www.ffiec.gov/hmdaadwebreport/aggwelcome.aspx

10. HMDA Website, (2008), http://www.stlouisfed.org/hmdaregcamendments/pages/glossary.html

11. Ho, G. and Pennington-Cross, A., (2006), "The Impact of Local Predatory Lending Laws on the Flow of Subprime Credit", http://research.stlouisfed.org/wp/2006/2006-009.pdf

12. Hogarth, J. M. and O’Donnell, K. H., (2000), "If You Build It, Will They Come? A Simulation of Financial Product Holdings Among Low-to-Moderate Income Households”, Journal of Consumer Policy, Vol. 23, pp. 409-444.

13. Mayer, C. and Pence, K., (2008), “Subprime Mortgages: What, Where, and to Whom?", Finance and Economic Discussion Series, Division of Research \& Statistics and Monetary Affairs, Federal Reserve Board, Washington, D.C., http://federalreserve.gov/pubs/feds/2008/200829/200829pap.pdf

14. McCoy, P.A. (2007), "The Home Mortgage Disclosure Act: A Synopsis and Recent Legislative History", Journal of Real Estate Research, Vol. 29, No. 4, pp. 381-397.

15. Mian, A. R. and Sufi, A., (2008), "The Consequences of Mortgage Credit Expansion: Evidence from the 2007 Mortgage Default Crisis", http://ssrn.com/abstract=1072304

16. Reade, J., (2006), "Home Mortgage Disclosure Act (HMDA) Home Purchase Data Summary for New England 2003”, Federal Reserve Bank of Boston Discussion Papers, http://www.bos.frb.org/commdev/pcadp/2006/pcadp0601.pdf

17. Rosenbaum, E., (1996), "Racial/Ethnic Difference in Home Ownership and Housing Quality, 1991”, Social Problems, Vol., No. 4, pp. 403-426.

18. Shiller, R. J., (2007), "Understanding Recent Trends in House Prices and Home Ownership", Cowles Foundation Discussion Paper No. 1630, http://ssrn.com/abstract=1017546 
NOTES 